\title{
Analysis about the path to improve the growth environment of rural children left behind
}

\author{
Chunlei ZHOU \\ Henan University of Traditional Chinese Medicine \\ Zhengzhou ,Henan ,450008,China
}

Abstract-With the profound changes in China's economic and social situation, the development model in rural areas has also undergone a sea change, a major change is that large numbers of people go out the countryside to work in developed cities, which significantly improve the living standards of farmers, but because of the limitations of this operating modes, the attendant is to produce a large number of rural left-behind children, these children now face the threat of personal safety, educational worrying, enduring the pain of missing family, which is obviously not conducive to the healthy growth of these children, not conducive to the stability of rural areas, and even affect our long-term development, and where is the way to solve it? Rural Children authors believe that the problem is not an isolated problem, this problem involves the change of entire rural environment and adjustment of national policy, there are needs the rural compulsory education, the adjustment for central focus of state urban development and the co-ordination force of new rural construction, and more pronged problems of rural left-behind children will be resolved gradually and fundamentally.

Keywords- left-behind Children in rural areas, new rural construction, local culture

\section{INTRODUCTION}

Since the end of 2011, China's urban population is 69079 , for the first time over the countryside. In recent years, China's urbanization rate quickly, urban functions are more and more perfect. In Contrast, the development of rural areas is relatively slow, the gap of urban-rural is always present, and it has the trend to expand. It is in this context, a large number of rural people flock to cities and towns, which directly contributed to the urbanization but caused new problems of rural areas, and the growing number of children left behind in rural areas has become an obvious and significant problems.

\section{CURRENT SituATION OF LEFT-BEHIND CHILDREN IN RURAL AREAS}

Compared with urban children, children from rural areas living in such environment with quiet and has strong local smell, which has a relatively superior environment, their growth are carefree and healthy. With the rapid development of China's economic and change in the social situation, the growth environment of children in rural areas has changed dramatically.

Since the development of China's urban significantly faster than rural areas, on the other hand the development of rural areas lagging behind, which resulted in a large number of labor force in rural areas flock to the town in recent years "according to the results of a sample survey estimated that in
2012 the national migrant workers total to reach 262.61 million, increased 983 million over the previous year, in which 163.36 million migrant workers, 9.925million are local migrant workers." this phenomenon has aroused profound adjustments in all aspects of China's vast rural areas. One of the significant influences is that appear large numbers of left behind children in rural areas.

Just because a large number of peasant workers are migrant workers, they have not settled into the town work at, often left the elderly and children in home, especially left young children. "Recently, the China Women's Federation issued a" national rural left-behind children, migrant children and rural status report. "The report shows that, according to the data from sixth national census in 2010, we estimate there are 61.026 million left behind children in rural areas, accounting for the proportion of all rural children up $37.7 \%$, accounting for $21.9 \%$ proportion of all children, compared with $1 \%$ nationwide sample survey estimates in 2005 , there were increased 242 million left behind children in rural areas within 5 years, the increase rate was $4.1 \%$."

\section{THE REALISTIC STRATEGY TO SOLVE THE PROBLEM OF LEFT-BEHIND CHILDREN IN RURAL AREAS}

\section{A. Comprehensive developing the medium and small towns, guiding migrant workers reflux small towns}

The reason why our country has as many as 260 million migrant workers work outside all year round, the primary reason is the attractiveness of urban employment, in essence, the adsorption capacity of the town's economy is stronger than it in rural areas. At present, a large number of migrant workers work outside and left their homes, from a national perspective, it has caused a lot of pressure on the big cities of our country, and the other small towns lack of relative development labor, especially the lack of a stable workforce development in central and western regions, in short, labor flows over cities is unreasonable, it has produced a number of negative effects.

Under the current circumstances, we should guide the migrant workers flow to small towns. First of all, the benefits of China's is that labor force distribution will be more reasonable, followed by help to narrow the gap between urban and rural areas, because the small towns are often close to rural areas, the development of small towns will help to drive the development of rural areas, if small towns successfully absorb large farmers workers, another benefit is in favor of the farmers better settled in small towns, then either left-behind children in rural areas will be taken care of easily, or left-behind children in rural areas will be able to easily settled with his parents in the small towns, rural 
children left behind will get their own original parent family back.

\section{B. continue to increase capital investment and support preferential policies for compulsory education in rural areas}

Compulsory education in rural areas should be increased all aspects of investment and support. China's current run of "special hillock teacher" system makes sense. the author believes that the investment in education in rural areas can only be overall increased not decreased. this work should be carried out under different circumstances In rural parts, such as increase more concentrated investment in rural population and establish exemplary schools to attract students enrolled; in the vast and remote rural areas should be evenly distributed teaching resources, as for the small population, also in urgent need of educational resources in rural areas should be chosen to support investment and commitment to high-quality education to keep the rural population, so that the local rural Children can also enjoy a good education. There are need to do the following aspects to:

\section{Strengthening rural compulsory education teaching faculty}

For a serious lack of qualified teachers in primary schools in rural areas, state should introduce more policies to encourage and send enough teachers to go to rural schools. In particular, the majority of young people should be encouraged to serve for rural compulsory education. of course, countries also need to introduce more supporting policies in this aspects, using policies to keep people, policies to encourage people, to really boost the rural compulsory education.

\section{Strengthening Rural Teachers' moral and ethos construction}

Currently individual teachers in rural areas appear to serious crimes underage students, such as sexual assault, etc., which have severely damaged the image of teachers', such events tend to occur in rural left-behind children, the impact and injury is particularly serious for rural left-behind children. For this purpose, the competent departments of education should decisively strengthen for the Teachers management in rural, and strengthen for teachers training, teachers teaching style aspects and make it become the regular work, should adhere to the principle called "postpedagogical, saving lives," and "recognition of advanced, punishment behind ", building a number of truly outstanding teachers in rural areas.

\section{STATE INTRODUCED POLICIES TO TAKE CARE OF RURAL LEFT -BEHIND CHILDREN}

States should introduce direct supporting policies to take care of children left behind in rural areas in some circumstances, so that they can feel the warmth from the state and society. In the long run, efforts should be made to explore suitable assistance, training mechanism for China's Rural Children to make this work normalized and institutionalized. China also made a positive attempt in this aspect.

"China Women's Federation announced that this year will invest 15 million Yuan in the establishment of 150 happy children left home, each home will be given 10 million to provide entertainment and a place to learn for the children left behind,." At the same time ACWF made clear that they will long-running children's homes.

"the responsible person of Civil Affairs Ministry showed that this year will explore the establishment of GSP's child welfare system, referring to orphans, s, paying the basic living expenses and establishing basic living allowance system to those who suffering from severe disability, or have parents but plight of missing home monitoring at the Second China-Cheer press conference. "

Authors believe that these two measures for rural leftbehind children will also have a positive impact on the country's children who need care, especially have a significant positive impact on the healthy development of children left behind in rural areas. Especially the establishment of the "left-behind children happy home", if the positive input, smooth operation, it will make long-term and positive social benefits.

\section{COMBINE ECO-AGRICULTURE AND ECO-TOURISM TO TAKE A NEW RURAL ROAD}

The implementation of this measure is to enable the rural population reflux, social capital inflows to rural areas, and ultimately for the construction of new rural services. With the rise of popularity in rural areas, funds ample gradually, rural areas will become a fertile ground for China's modernization once again.

Construction of ecological agriculture should become a priority choice in rural areas. under the current background of that people are concerned about their health, concerns the quality of life, the agricultural products of original ecology have been popular, rural areas as the main front of various types of agricultural production should be reversed ideas, and actively explore the production model to suit local conditions, returning to the original ecological agricultural production operations, reducing the use of chemical fertilizers, pesticides, producing organic food, doing business in organic food, exploring the road of agricultural processing products.

Eco-tourism will have a concrete analysis about specific issues, to engage in eco-tourism in suitable areas, or engage in eco-tourism in developed areas by moderately, if ecotourism actively carried out, which will significantly promote rural economic development and social progress, and it will attract the exodus return to rural.

In short, these two measures will significantly enhance the economic vitality, social vitality of rural areas, cultivate new growth point of the rural economy, the construction of new rural developed smoothly, obviously it will be beneficial to solve the problem of rural left-behind children. 


\section{THE VISION DESIGN ABOUT SOLVING THE PROBLEM OF RURAL LEFT-BEHIND CHILDREN}

Solve the problem of children left behind in rural areas is to solve the problem of rural development. it requires efforts on two fronts. One is the economic development level and the other is a revival of the cultural dimension.

\section{A. Aspects of economic development}

The author believes that we should take full advantage of our current tide of urbanization, especially should focus on the development of urbanization in small towns, which conclusions from our consideration of environmental pressures and urban layout. Because of the geographical reasons, it will be obvious to spur economic development in rural areas in the development process of Small towns.

New rural construction should be promoted, which will directly enhance the economic level in rural areas. At present, a lot of young labor force in rural areas outflow, one of the main reasons is economically backward in rural areas, so it is very important do everything possible to invigorate the economy in rural areas. Agricultural production is the most important factor to Invigorate the rural economy, enliven rural land and continue to promote the reform of rural land system, develop the new agricultural production patterns, and take the path of ecological agriculture.

\section{B. Revival of the cultural dimensions}

Construction of rural areas cannot just stay at the economic level, but also focus on the culture level, which is a comprehensive rural development. There are special features of culture to cohere peoples' heart, and the vast rural areas have strong local culture, clan culture, civilization and geographical characteristics, which are undoubtedly the best choice for the cohesion of people. Material things easily fade away, and cultures always tend to endure.

Due to the complex reasons, many of China's rural areas appear more or less faults in continuation of the local culture, which largely resulted outflow of population in rural areas, or unable to retain people. Many rural young peoples' concept of local culture is very weak, then how to expect them to stay in the rural areas for building at ease?

Perhaps we can get reference from our neighbor Japan for the preservation of local culture, and they attached great importance to the protection of their own folk culture. As an important part of folk culture - rural culture, Japan is considered to retain its traditions and the revival of national priority. Currently, most rural Japanese village built as museum for traditional skills to master, veteran artists regarded as " National Living Treasure", after identified their specialized skills, the state will consider to set aside special funds, record his art, save his work, teach skills, train successor, improve his living conditions and for art.

China has a long history and culture, including the country also rural areas have many historical and cultural relics, the vast rural areas have strong local culture, on the road leading to the great rejuvenation of the Chinese nation, we have a responsibility to inherit these precious cultural heritage, carry forward the majority of these distinctive local culture, to educate, influence with a strong local culture, making the contemporary people, especially the rural population in rural areas have a deep love of culture, have the constant "nostalgia."

\section{SIGNIFICANCE OF SOLVING THE PROBLEM OF RURAL LEFT-BEHIND CHILDREN}

Rural Children problem is not a separate issue, but with a range of issues associated social problems, an important part in livelihood issues and political issues, so the way to this problem should be a global thinking, then solve it well, it will has a broad meaning.

Children in special period, they need special care and attention. Rural children left behind due to the long-term lack of parental care, comprehensive development of children will be subject to a variety of negative effects. If, pursuant to the above, after promoting the practical measures, I believe that rural children left behind will get more valuable parent family, or solve the long separation case of parents and children left behind in rural areas, and children left their parents will get a complete family education. Meanwhile, with the education condition of the children has been significantly improved, security environment even overall environment in rural areas were improved, these will good for their healthy growth, overall growth and lay a solid foundation.

Children are every family's hope and if the problem of rural children left behind gradually resolved in the state, society and schools to work together left-behind children in home can receive a good education, has a secure and stable environment, rural family stability is inevitably further enhanced, the development of this family will become prosperous. Rural family stability necessarily conducive to stability in rural areas, it can be expected that improve the stability of the rural family will benefit the development of rural areas, in turn, the development of rural areas led to further stabilize the rural areas. Both of them will enter a virtuous cycle.

\section{CONCLUSIONS}

China's vast rural areas $\mathrm{t}$ is also promising in development of economy, and has potential development power, taking measures around the rural children left behind will improve the environment, the vitality of rural areas will burst again, which will stimulate economic growth in the entire country, and has become the new era breakthrough of economic growth.

\section{References}

[1] Duan Chenlong; Yang Ge Status of Children Left in Rural China [J] Population Studies, 2008 (3).

[2] Nan Huaijin[M] Beijing: Commercial Press, 2012.12.

[3] Jiang Junjie missing and social work education in rural children left behind family intervention research [D] Wuhan: Huazhong Agricultural University, 2012. 